\title{
Entrevista ao arquiteto Ricardo Bak Gordon
}

\author{
Filipa Ramalhete \\ framalhete@autonoma.pt \\ Centro de Estudos de Arquitetura, Cidade e Território da Universidade Autónoma de Lisboa \\ (CEACT/UAL), Portugal | Centro Interdisciplinar de Ciências Sociais da Universidade Nova de \\ Lisboa (CICS.Nova) \\ Marta Sequeira \\ martasequeiracarneiro@gmail.com \\ Professora Auxiliar Convidada Da/UAL | Professora Auxiliar Convidada ISCTE-IUL \\ |lnvestigadora Integrada CIAUD-FAUL
}

Para citação: RAMALHETE, Filipa; SEQUEIRA, Marta - Entrevista ao arquiteto Ricardo Bak Gordon. Estudo Prévio 17. Lisboa: CEACT/UAL - Centro de Estudos de Arquitetura, Cidade e Território da Universidade Autónoma de Lisboa, 2019. ISSN: 2182-4339 [Disponível em: www.estudoprevio.net]. DOI: https://doi.org/10.26619/2182-4339/17.1

Creative Commons, licença CC BY-4.0: https://creativecommons.org/licenses/by/4.0/

É com enorme prazer que temos connosco o arquiteto e professor Ricardo Bak Gordon. Seja bem-vindo. Queremos começar por pedir que nos contes um pouco como foi o teu percurso académico, como aluno, os professores e os exercícios mais marcantes.

Começando pelo curso de arquitetura, tive a felicidade de, por me faltarem três décimas para entrar na Universidade em Lisboa, ir parar à escola do Porto. Tinha pouca ideia do que era a disciplina e o ensino da arquitetura. Embora já tivesse estudado na escola de artes António Arroio - foi nessa altura que me interessei pela disciplina de arquitetura-, estava longe de conhecer a disciplina ou ter contacto com os seus protagonistas.

Por falta dessas três décimas, fui parar ao Porto. Isso correspondeu não só a uma descoberta extraordinária da faculdade de arquitetura da Universidade do Porto (com tudo o que isso implica), mas também à primeira saída de casa, que é uma outra maneira de dar início à prática da arquitetura - conseguir olhar para um lugar e vê-lo 
pela primeira vez. Tenho o sonho (costumo dizer que é o único sonho irrealizável que tenho) de chegar um dia a Lisboa e vê-la pela primeira vez. Mas tinha de sofrer de uma doença patológica para poder descobrir Lisboa dessa maneira!

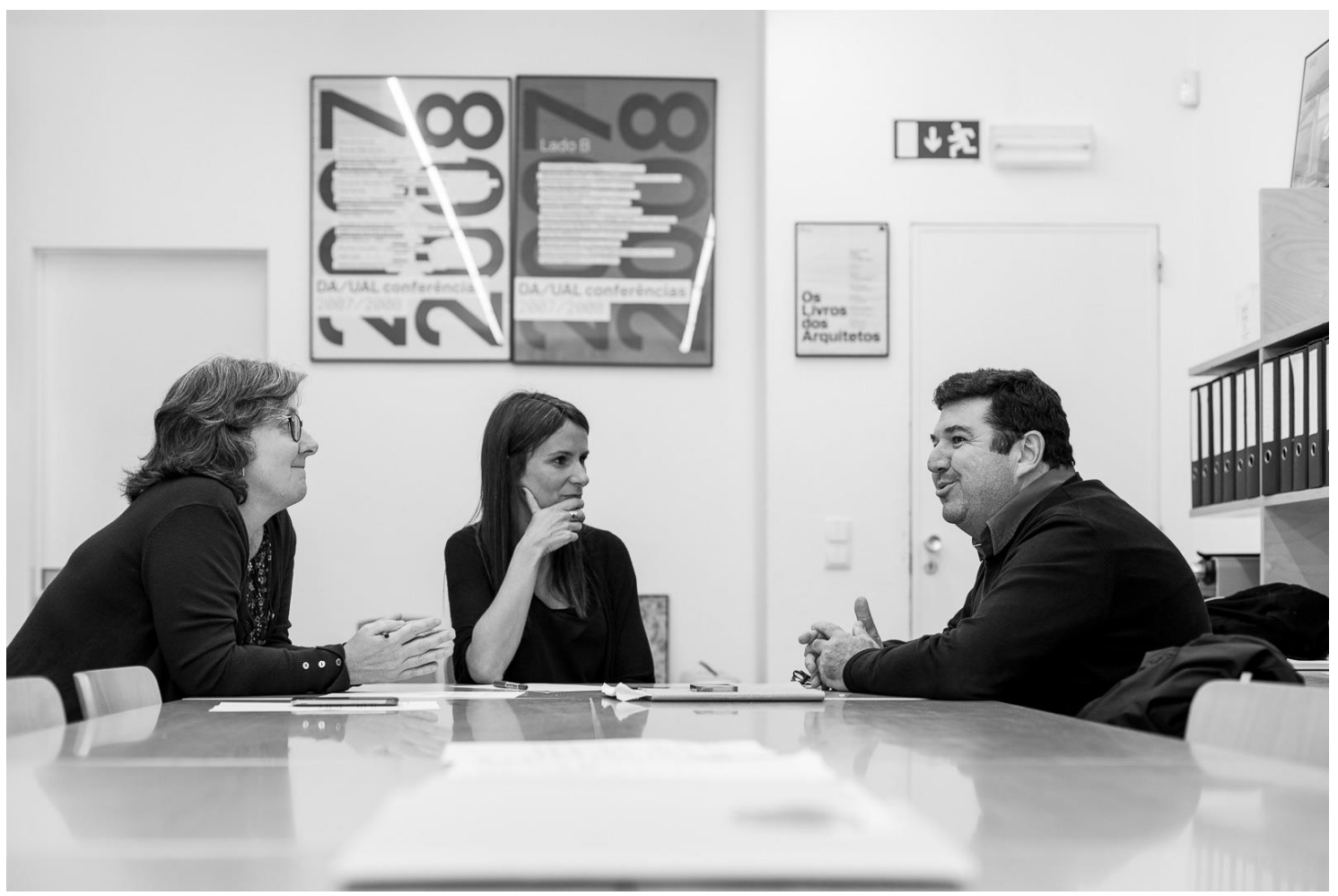

(c)Gonçalo Henriques + Estudo Prévio

Fui então para o Porto, e não só tive a experiência de conhecer a cidade, como tive a experiência de descobrir uma escola incrível, que tinha no primeiro ano o tema do "desenho como linguagem e como expressão". Era talvez a disciplina mais forte daquele primeiro ano, a questão do desenho absorvia quase por inteiro a experiência dos alunos. $E$ também tive a experiência de começar a conhecer as personagens $e$ figuras de quem nunca tinha ouvido falar, uma delas a mais paradigmática: o arquiteto Álvaro Siza. E, finalmente, também tive a experiência de um coletivo e da relação professor/aluno, que era bastante íntima no Porto e que me marcou. Inclusive na minha vida, enquanto professor, pratico um tipo de aproximação com os alunos que vem desde aí. Havia, de facto, uma grande intimidade, estávamos todos juntos numa grande sala com todos os professores, e acontecia uma coisa extraordinária, que nunca mais vi repetir-se nas outras universidades por onde andei, que era professores e alunos tratarem-se por tu, uma coisa que só existia no território anglo-saxónico, porque em Portugal, naquela altura, em nenhuma escola acontecia.

Isto passou-se em 1985/86. No final do primeiro ano, pedi transferência para vir para Lisboa porque, embora tivesse gostado imenso da experiência, eu era de Lisboa, e estar no Porto correspondia a uma despesa acrescida. Fiquei muito feliz por ter 
tomado essa decisão, porque o Porto era um sítio para "ir e vir" e não para ficar lá (no que diz respeito aos estudos).

Vim para Lisboa e sofri um grande choque. As realidades culturais e académicas eram muito diferentes. Vinha de uma escola onde se acabavam de divulgar os ensaios sobre a obra do arquiteto Siza Vieira e o Regionalismo Crítico do Kenneth Frampton, e chegava a uma escola onde os heróis eram Michael Graves e o arquiteto Tomás Taveira. Isto dá uma ideia de como uma pessoa pode ser confrontada com dois territórios tão distintos de formação e ter a necessidade de se adaptar. Isso obrigoume também a perceber as virtudes e inconvenientes de cada um destes lugares.

Mais tarde, fui pioneiro do programa Erasmus (que começou em 1988, celebrou há pouco tempo os 30 anos). Um dia, estava na Escola de Belas Artes, no Convento de São Francisco, onde tínhamos aulas, e alguém disse: "Vão fazer ali umas entrevistas para um programa de intercâmbio cultural, que é para que os alunos possam ir trabalhar para outras Universidades". Eu, mais ou menos às cegas (que é uma marca da minha vida), atirei-me para a fila onde estavam a fazer as entrevistas e saí de lá selecionado. Cheguei a casa e disse à minha mãe que tinha sido selecionado para ir um ano estudar para o politécnico de Milão.

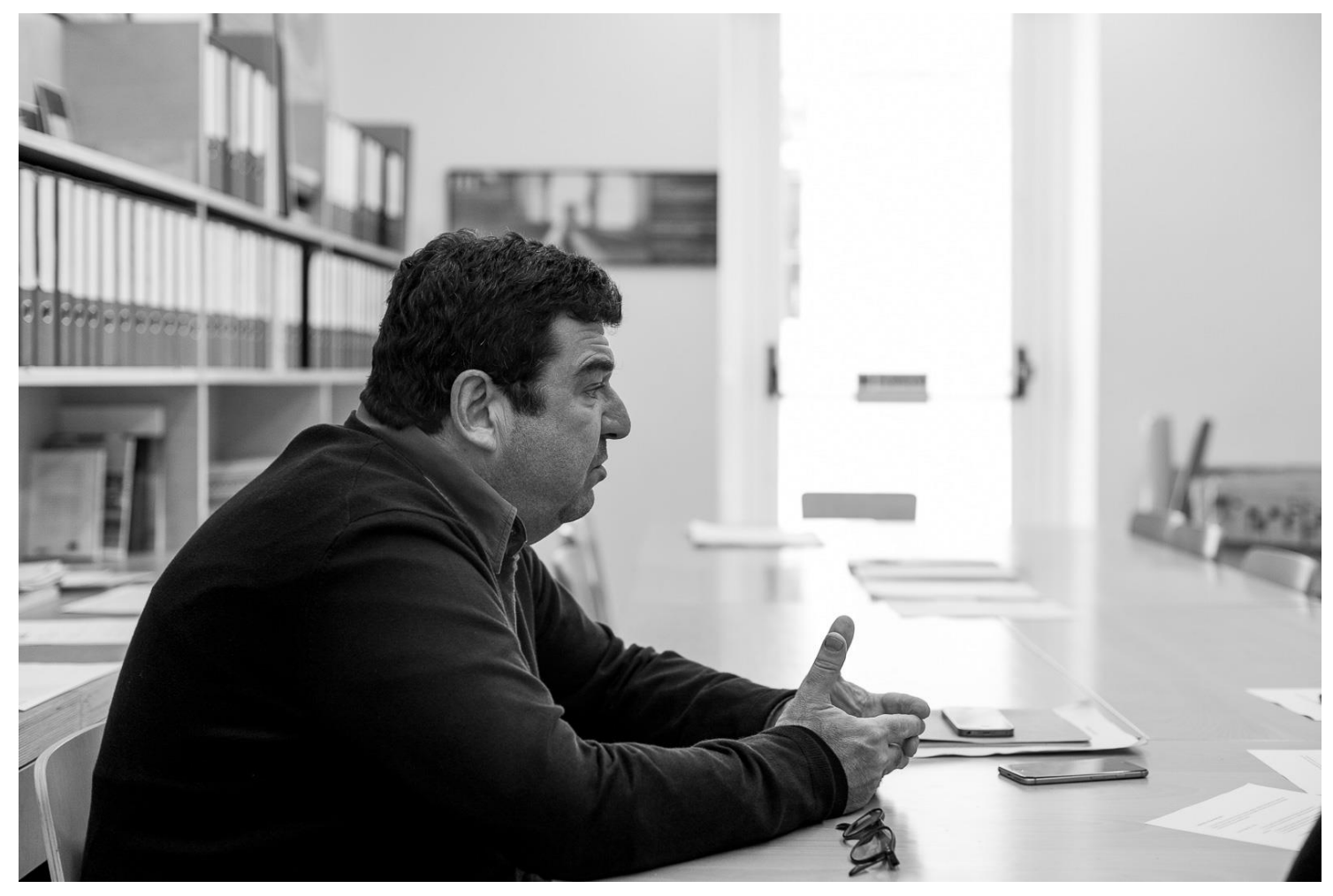

(c)Gonçalo Henriques + Estudo Prévio 
Assim se sintetiza o meu percurso académico, que passa por estas três escolas e pelas experiências muito diferentes das três escolas. Em todas elas encontro virtudes. No caso do politécnico de Milão, as aulas de projeto eram uma coisa muito secundarizada, em relação a outros interesses que a escola tinha. A escola oferecia um ciclo de conferências como não havia em Portugal; num dia estava o Rem Koolhaas, noutro falava o Tadao Ando - e outras pessoas extraordinárias, com quem podíamos ter uma relação próxima. A escola tinha uma livraria de arquitetura como não existia em Portugal nada que se parecesse. Eu passava as minhas tardes ali, foi onde vi, li e conheci desde o Palladio ao Aldo Rossi aos desconstrutivistas (o famoso livro cor de laranja...). Conheci tudo isso nas tardes infinitas que ali passava.

Por fim, estava no centro da Europa! A duas horas de distância de cinco ou sete países. Viajei muito. No fim, o que retiro, o que é muito rico, é que não tenho uma formação numa única escola ou lugar. Não sobrevalorizei uma escola, figura, momento ou lugar em detrimento de outros. O que me deixou um certo autodidatismo, como um caçador-recoletor, que vai andando e pegando no melhor que vai encontrando na paisagem por onde vai atravessando.

Relativamente ao Porto, houve uma série de pessoas que, na mesma altura, fizeram um percurso relativamente semelhante ao teu. Começaram o curso no Porto e depois voltaram para Lisboa. São hoje arquitetos com uma obra bastante reconhecida, com atelier em Lisboa. Acabou por ser um processo - "ir ao Porto e depois voltar". Não sei se gostavas de falar um pouco mais sobre esta ideia.

$\mathrm{Na}$ altura, a escola do Porto tinha uma média inferior à de Lisboa. Foi por isso que eu e algumas pessoas lá fomos parar. Admito que a outras, mais instruídas ou mais elucidadas sobre as virtudes da escola do Porto - estou a lembrar-me de arquitetos, filhos de pais arquitetos, que já sabiam quem era o Álvaro Siza, Fernando Távora, já sabiam o que era a escola do Porto -a família ajudou tenha ajudado a tomar decisões, a apontar um caminho. Um caminho que era naturalmente a escola do Porto porque, conhecendo aquele período da história como nós a conhecemos, outra coisa não faria sentido.

Eu gostei imenso do ano em que lá estive, gostei imenso do que aprendi lá. Refiro-me a essa aprendizagem que está muito para lá da arquitetura, que se estende muito para lá dos limites do que possa ser a aprendizagem, o ensino, a prática da arquitetura e a pedagogia da arquitetura. A relação humana entre as comunidades escolares aprendi lá, nunca mais voltei a vivê-la de uma forma tão intensa e íntima. Isso é um valor imprescindível da minha vida académica. Outro valor imprescindível é o desenho como comunicação; eu continuo a desenhar todos os dias. Lembro-me perfeitamente do dia em que me sentei e me disseram: "Aprender a desenhar é como aprender a falar mandarim. Não há jeito para o desenho! Isto é para se aprender a fazer e, uma vez conquistada esta linguagem, vais descobrir que é a linguagem mais rápida de investigação da arquitetura". 
O desenho é a segunda linguagem mais rápida, a mais rápida mesmo é o nosso sonho e o nosso pensamento.

Tive como professor de desenho o escultor José Grado. Era um professor mítico, que se amava ou odiava. Era muito forte, chegava a ser violento, no modo como se relacionava com os alunos. Para mim, foi uma descoberta incrível - aquela metodologia de trabalhar, a usar o desenho, é uma coisa que dificilmente imagino não praticar. Apesar de sabermos que a arquitetura é investigada de múltiplas formas, e que o desenho não é o único modo de fazer investigação (Jaque Herzog orgulha-se de dizer que não desenha). Para mim, é um tema muito importante, que trouxe do Porto... Mas trouxe muitos outros.

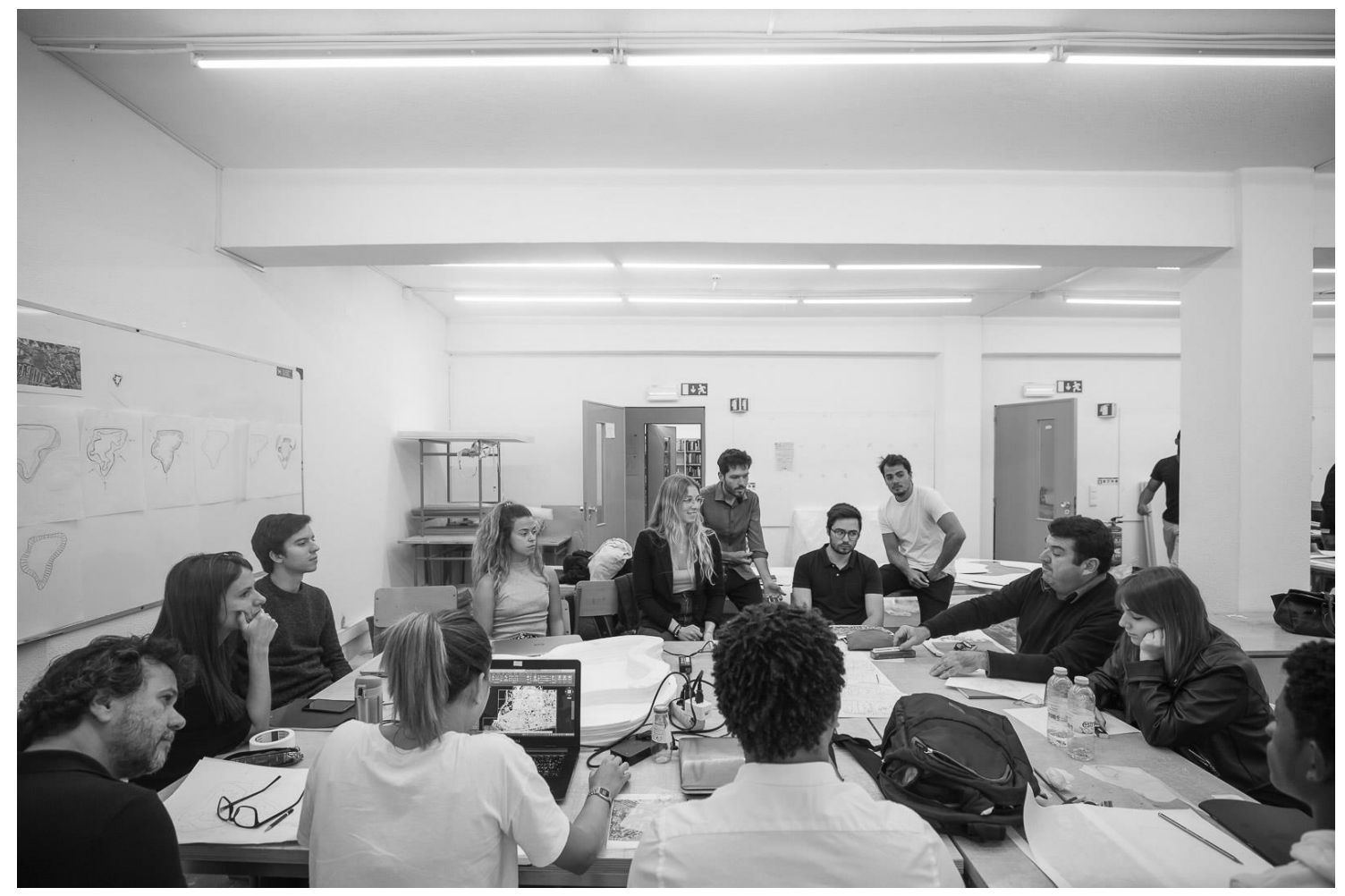

(C)Gonçalo Henriques + Estudo Prévio

Nas várias entrevistas que já fizemos, os arquitetos falam muitas vezes nessa descoberta de olhares novos, de disciplinas novas, como no caso do Desenho, como referiste. Houve também outras áreas?

Outras áreas... Posso dizer que talvez até se tenha ainda sobreposto a esse encanto sobre a descoberta do desenho, a figura do arquiteto Fernando Távora enquanto professor. Olhando para trás foi talvez uma das pessoas mais marcantes do tempo em que andei a estudar, de todas as universidades por onde passei. A maneira como ele nos ensinava a pensar e falar sobre arquitetura, de uma forma muito apaixonada, mas também muito simples. 
Julgo que um dos temas que é importante na arquitetura é a capacidade de síntese e simplificação dos seus conteúdos. Somos interlocutores com os alunos - e com uma comunidade alargada (cidadão, habitantes do universo) -, vamos falar de uma disciplina e, por isso, é sempre bem-vinda a capacidade que possamos ter de transmitir o conteúdo de forma simples para que a mensagem chegue aos outros. Não havia nada mais extraordinário do que ouvir o professor Távora a desenhar e a contar as histórias: a contar como eram sete irmãos; a falar sobre o desgaste das solas dos sapatos, que passavam de um irmão para o outro; a falar das pedras da calçada e do desgaste da pedra da Igreja... Uma série de ensinamentos a partir de coisas reais, simples, coisas da vida, ditas de um modo apaixonante, e com um olhar poético sobre o mundo. O olhar poético é algo que não podemos perder, sob pena de nos tornarmos uns tecnocratas -coisa que queremos evitar.

\section{Esse talvez até possa ser o grande ensinamento de uma escola de arquitetura.}

Sim, acima de qualquer outro.

\section{E como é que passas isso para as tuas aulas?}

Talvez devêssemos perguntar aos meus alunos. Como é que eu quero acreditar que passo? Primeiro, fazendo as pessoas sonhar e desejar aquilo em que se vão envolver. Antes de mais, partir do ponto zero, que é a entrega ao que podemos produzir, que ainda não existe ainda, algo que vai ser um contributo positivo para a nossa vida e para a vida das pessoas que estão connosco e para os lugares que vamos transformar. É esse entusiasmo e visão poética que procuro transmitir.

Depois, há outras regras que encontro como guião em todos os projetos e participações em que vou tendo posição ativa no ensino, e que têm a ver com estruturar o projeto em três fases muito claras. A primeira fase é sempre sobre 0 princípio de que não é possível fazer um projeto sem ter uma ideia estratégica. Para esta fase, podemos usar palavras como "conceito", "estratégia", ideia" - as palavras vão mudando ao longo do tempo, saem do circuito porque deixam de estar na moda. Ao contrário de algumas memórias dos tempos primeiros da escola, em que nos sentávamos à frente do papel vegetal e, sem pensar, tirávamos linhas e tentávamos perceber se surgia alguma coisa (refuto determinantemente esse princípio), eu quero que a pessoa, antes de fazer seja o que for, consiga identificar a semente de uma ideia.

Essa semente é que vai permitir começar a percorrer o caminho da investigação e transformar uma ideia num projeto de arquitetura. Esse período é longo, as primeiras imagens são nebulosas (é como o nosso feto na barriga da nossa mãe, primeiro são só umas células sem forma, mas que são tudo, já lá está tudo, só não se vê ainda). Depois, surge o caminho da investigação, maturação e desenvolvimento, até a coisa se transformar no projeto.

Finalmente, mais uma vez, a questão da comunicação. Os projetos servem para comunicar, vão comunicar por si só, não vamos estar lá para os defender, nem a falar 
sobre eles, vão ter a sua própria vida. Vão ter a uma vida própria, porque um dia vão para um concurso, vão para uma câmara municipal, vão ser licenciados, vão encontrar os seus clientes (talvez aqui tenhas a hipótese de estar ao lado deles e defendê-lo com a própria voz); e, depois, vão ter outras vidas, tão variadas como serem uma obra (onde não estás presente), ou serem estudados, se tudo correr bem, daqui a 50 anos (onde não podes estar mais presente). A linguagem e a comunicação são um grande tema. Por isso, peço aos meus alunos que falem, que falem e que falem. Falem comigo e falem com o espelho.... E só ao fim de falarem três vezes com o espelho é que vão decantando a ideia, e a ideia vai ganhando mais essência e densidade. $O$ processo de decante é de tentar filtrar, filtrar, e obrigar a construir a mesma frase, várias vezes, até que ela seja precisa.

\section{É como se estivesse a ensinar o seu próprio projeto. Porque a ensinar aprende-se sempre.}

\section{Exatamente.}

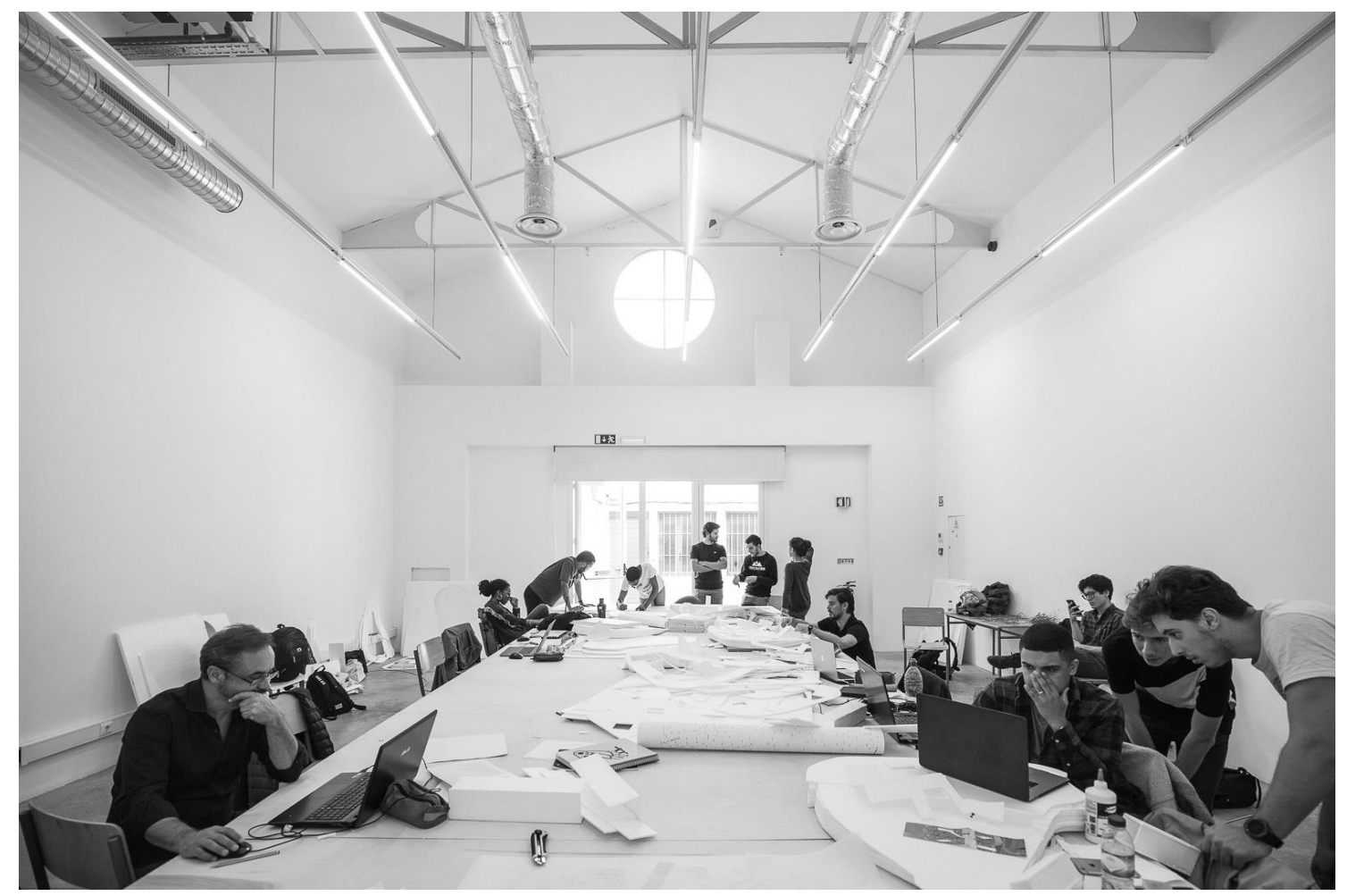

Co Gonçalo Henriques + Estudo Prévio

Será que nos podias falar um pouco sobre o que propuseste no workshop que estás a realizar no Da/UAL [outubro de 2019]? 
Este workshop tem várias características, parece-me algo inédito aqui na UAL. Chamamos-Ihe Estúdio Vertical. É a primeira vez que se faz um workshop em que todos os alunos estão a trabalhar em conjunto, em grupos de trabalho compostos por alunos de todos os anos. Isto é algo inédito e, por si só, é uma experiência extraordinária. Por os alunos do $1^{\circ}$ ano ao mesmo nível que os alunos do $5^{\circ}$ ano, todos a colaborar, a poder participar com as suas ideias, e a descobrir o que os distingue, nos diversos anos, e o que é comum às preocupações do projeto, independentemente do ano.

O que nós propusemos foi dar atenção ao que têm sido as preocupações da cidade de Lisboa, através dos grandes grupos de temas ligados à urbanidade da cidade. Atravessámos uma crise importante em Portugal e, nessa altura, surgiram algumas ações e reações, como o fenómeno turístico, que explodiu em Lisboa. Durante um período, os dirigentes municipais tentaram apoiar o fenómeno turístico de várias maneiras, essa mesma oportunidade para deitar mão ao espaço público da cidade, que merecia pouca atenção por parte do município. Todos nós conhecemos o programa "Uma praça em cada bairro", através do qual vimos uma série de espaços na cidade serem reabilitados. Vimos também um outro fenómeno, que tem duas maneiras de ser olhado uma inevitavelmente positiva - uma quantidade de áreas da cidade, que são património histórico edificado e estavam a cair de podres, e que a reabilitação urbana atacou em força, muitas vezes pelas mãos dos próprios utilizadores, outras pela mão de fundos de investimento. Que também um bocadinho responsáveis por aquilo que chamamos de gentrificação, mas temos de pesar os prós e os contras desse tema.

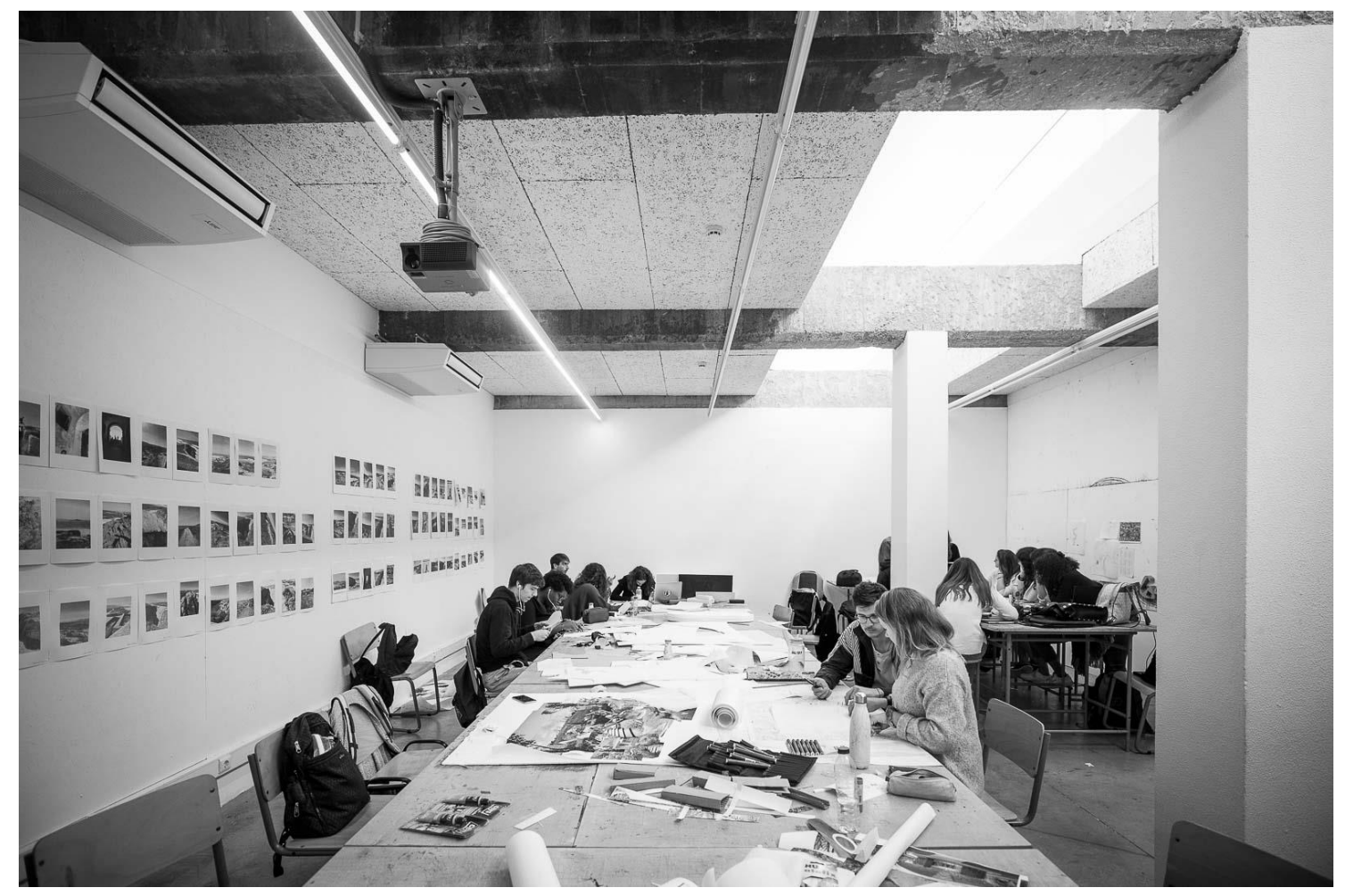


(C)Gonçalo Henriques + Estudo Prévio

$\mathrm{Na}$ consequência desse fenómeno, chegamos a uma outra preocupação que, neste momento, é mais ou menos consensual - a falta de habitação nas cidades. Quando nos pomos a pensar nisso, não é possível esquecer os vários momentos, desde o movimento moderno - que é quando a cidade mais se consolida e se transforma em metrópole-, ao final dos processos de êxodo rural. Houve, de facto, períodos em que a cidade de Lisboa experimentou uma série de modelos e se dedicou à habitação coletiva: os modelos dos anos 30 e 40, mais tarde os do movimento moderno, nos anos 60 e 70; depois, os instrumentos públicos para trabalhar sobre a questão da habitação coletiva. $\mathrm{E}$, depois, parece que entrámos numa espécie de território de silêncio, em que nunca mais ninguém quis falar do tema da habitação, deixou de ser assunto. Foi relegado exclusivamente para o campo dos privados e, portanto, parece que deixou de ser disciplinar quando, afinal de contas, devia ser a matriz de todas as disciplinas. Porque as cidades são feitas de casas e não de outra coisa. É muito bom visitar a torre Eiffel e o Museu do Prado, mas o que faz as cidades, e o que as constrói, são as casas, e, portanto, são precisas casas para as pessoas.

O que viemos aqui propor foi voltar a refletir no tema da habitação coletiva, num território que tem uma marca bastante interessante. Não procurámos um território de conflito - como muitas vezes se faz, pôr os alunos a refletir sobre territórios de conflito, com grandes tensões, sejam elas geográficas ou sociais. Aqui, estamos a trabalhar um território muito agradável, de expansão natural da cidade, que é um "lugar", ao contrário de muitos territórios onde a cidade cresceu, que continuam a ter uma marca de "não-lugares" - veja-se algumas situações mais periféricas, nos eixos das estradas que vão de Lisboa a Sintra, ou de Lisboa na direção a noroeste, e mesmo a sul do Tejo, onde houve muitos momentos em que a cidade cresceu sem qualquer planeamento.

O Alto do Restelo é um território muito marcante e simbólico, para já porque tem 500 anos de história reconhecível, e também porque, em redor deste lote de terreno (com 25 mil metros de área de implantação), existem uma série de tipologias habitacionais que podem permitir aos alunos ter a perceção de como a habitação coletiva vai sendo abordada ao longo dos tempos, deixando-os com modelos, mas também percebendo que não há só um caminho, dando-lhes liberdade para que possam fazer uma proposta atual sobre habitação coletiva.

\section{E como é que te parece que os alunos têm respondido a este tema?}

Os alunos estão a reagir muito bem. O workshop está a viver um momento muito entusiasmante. Vejo os alunos e os grupos muito dinâmicos. Julgo que há várias componentes a concorrer para este resultado, seguramente que uma delas é o facto de estarmos a falar desta tipologia do grupo vertical, ou seja, dos grupos dos vários anos estarem todos juntos a trabalhar. Por outro lado, é um grupo de alunos cuja sua origem é muito ampla e variada, veem-se alunos de muitos lugares do mundo, o que dá uma atmosfera internacional ao seminário. Finalmente parece-me que os resultados que vão sair vão ser positivos, entusiasmantes e vão, sem dúvida alguma, ser marcantes para o percurso académico dos alunos. 


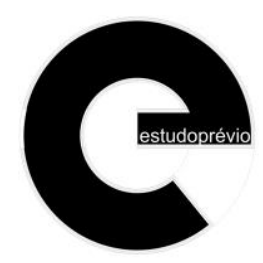

PT | E01 | EP17 | s2020

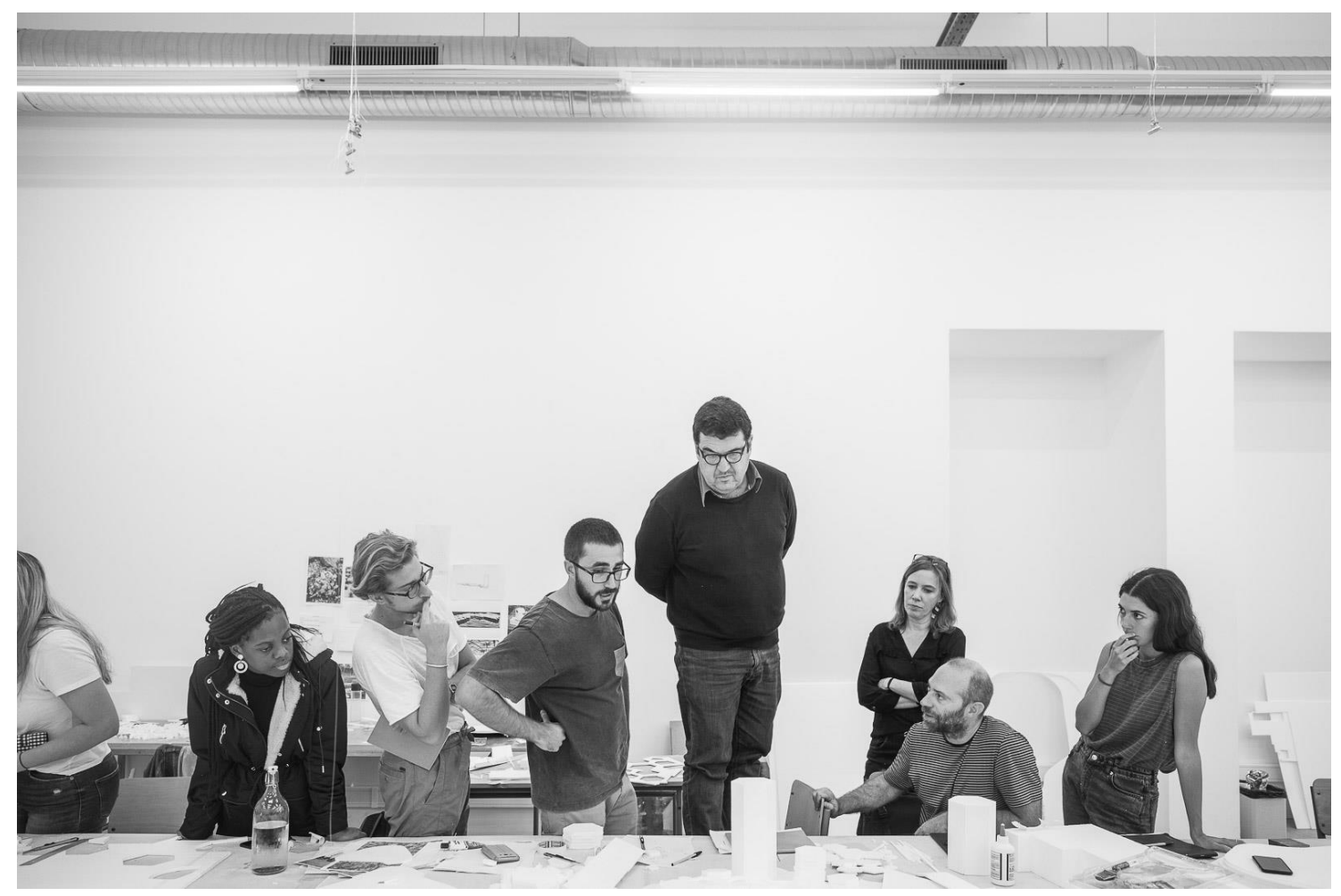

(c)Gonçalo Henriques + Estudo Prévio

Deste aulas em várias escolas de arquitetura, não só em Portugal como pelo mundo. Tens uma visão ampla do panorama do ensino e aprendizagem da arquitetura. Foste tu próprio aluno estrangeiro. Como é que vês esta escola e como olhas para estes alunos (agora especialmente nesta semana mais próxima e intensa)?

Tenho, de facto, uma visão alargada sobre o ensino da arquitetura. Não só porque dei aulas em Portugal e fora, em várias geografias e continentes, mas também porque, no meu trabalho, já vi muitas escolas a trabalhar, como visiting critic. Acho que a UAL tem uma característica muito peculiar, que tem a ver, por um lado, com a escala, e, por outro, com o seu corpo docente. Há muita unidade neste corpo docente. Essa unidade vem de ser um grupo. Conheço outros casos assim e, em geral, são casos de sucesso. Sinto que a UAL é um grupo de amigos que fizeram uma escola (no melhor sentido da expressão), são pessoas que têm interesses comuns, claro que com as suas diferenças, mas que têm uma maneira de olhar para o mundo, e uma visão sobre o universo, partilhada entre eles - e eles são os líderes desta escola. Têm respeito pelo trabalho uns dos outros, que é uma coisa importantíssima; têm um trabalho respeitado e respeitável como autores arquitetos, não só como docentes. Há poucas franjas de perda naquilo que é o património do corpo docente, e refiro-me principalmente aquilo que é a estrutura docente da escola. Muitas vezes, nas outras escolas, é onde podes encontrar mais dispersão: identificas autores e professores que valorizas, no meio de uma espécie de nebulosa menos clara ou menos criteriosa. Acho que aqui há muita gente boa por metro quadrado! Nesse sentido, o resultado 
está à vista, estou muito satisfeito e entusiasmado por, ao fim de $48 \mathrm{~h}$, ter uma escola inteira a fazer maquetes, a discutir arquitetura, entusiasmada, a perceber o que são os grandes temas que estão a discutir, a trabalhar com entusiasmo e a acreditar que vale a pena. Por isso, acho que a escola, o seu corpo docente e o seu corpo discente, estão preparados para fazer bem em qualquer circunstância.

\section{O que retiras de experiências como este workshop ou do ensino em geral, para a tua própria experiência como arquiteto profissional que faz projeto?}

Eu não sou propriamente um daqueles professores que leva para a escola as suas inquietações arquitetónicas - pelo menos num discurso direto ou de forma imediata, como sabemos que existem. Conhecemos muitos professores que têm trabalhos em que estão envolvidos e que procuram transportar para os ateliers-laboratório as coisas que mais os preocupam na disciplina.

Eu olho para isto com uma experiência pessoal muito enriquecedora, como olho normalmente para a minha atividade académica em geral. Em relação aos meus alunos, procuro ser uma espécie de condutor de música, eu não quero fazer os meus projetos com os meus alunos, quero que eles façam os projetos deles e ajudá-los a verem melhor o caminho. O que eu retiro é um grande prazer e encantamento e, de facto, uma motivação. São atmosferas de grande entusiasmo e de grande capacidade transformativa; isto alimenta-me imenso e saio daqui com imensa energia para fazer outras coisas que tenho de fazer.

\section{Há pouco dizias que os alunos estão prontos para sair para qualquer lado. Vês diferenças muito substanciais entre o início da tua vida profissional e os desafios e o contexto em que os alunos hoje trabalham?}

Vejo, vejo diferenças abissais. No tempo em que eu fui estudante, todos nós trabalhávamos durante o curso todo em ateliers de arquitetura, era uma coisa completamente natural. Hoje em dia, o ensino multiplicou-se, mercê de várias razões, mas uma delas é o ensino ter-se privatizado - só havia 3 escolas de arquitetura naquela época e agora há 23. Isto não é um fenómeno só português, é internacional. Portanto, a relação entre o número de estudantes e o número de ateliers que tem capacidade de receber alunos é mais difícil (para lá de outros temas, como o tema laboral, e outros, que complicaram as relações mais informais que existiam). Eu trabalhei o curso todo, desde o segundo ano. Fui colaborando em ateliers, como outros colegas. Hoje, há muitos miúdos que chegam ao $5^{\circ}$ ano sem nunca terem entrado num atelier de arquitetura. Só essa diferença é enorme - não poderes ter uma relação mais ou menos permanente entre a prática e a escola. Nós trabalhávamos à noite, íamos às aulas de manhã, íamos para o atelier à tarde - tudo com uma relação muito próxima. Quando acabávamos o curso, havia um percurso de continuidade. Hoje em dia essa continuidade não só não existe como há uma espécie de vazio, ou um momento de grande pânico, quando os miúdos acabam a escola. Porque os ateliers não podem receber toda a gente que se forma, porque ainda não fizemos um trabalho que devia ser feito, que é perceber que a formação em arquitetura é uma formação muito rica e que podia ocupar uma serie de outras posições na sociedade e na 
comunidade que não apenas abrir um atelier ou ir trabalhar para um atelier. Os arquitetos fazem falta em muitos lugares onde ainda não estão a ser utilizados e, nessa perspetiva, julgo que há muito trabalho a fazer.

Depois, há outras partes positivas nesta história, quem têm a ver com a forma como olhamos para a geografia infinita como a nossa casa. As pessoas não saem porque têm de sair, saem porque é natural sair e voltar a entrar. As portas estão abertas, 0 território é único. O Erasmus ofereceu isso, que não existia antes, cruzas-te com outras realidades, depois recebes cá os amigos de Erasmus que veem... Portanto, acho que as condições são muito diferentes, é muito diferente começar. Não sei se é mais difícil começar ou se começas de outra maneira. Agora cada vez somos mais, estamos a lutar para ter rácios de formação superior equiparados ao ranking mundial. Desde os anos 70 em que andávamos a lutar contra o analfabetismo (somos um país que, ontem à tarde, tinha $70 \%$ de analfabetos...), estamos a crescer de uma forma muito acentuada e, portanto, temos de nos ir adaptando a essa condição.

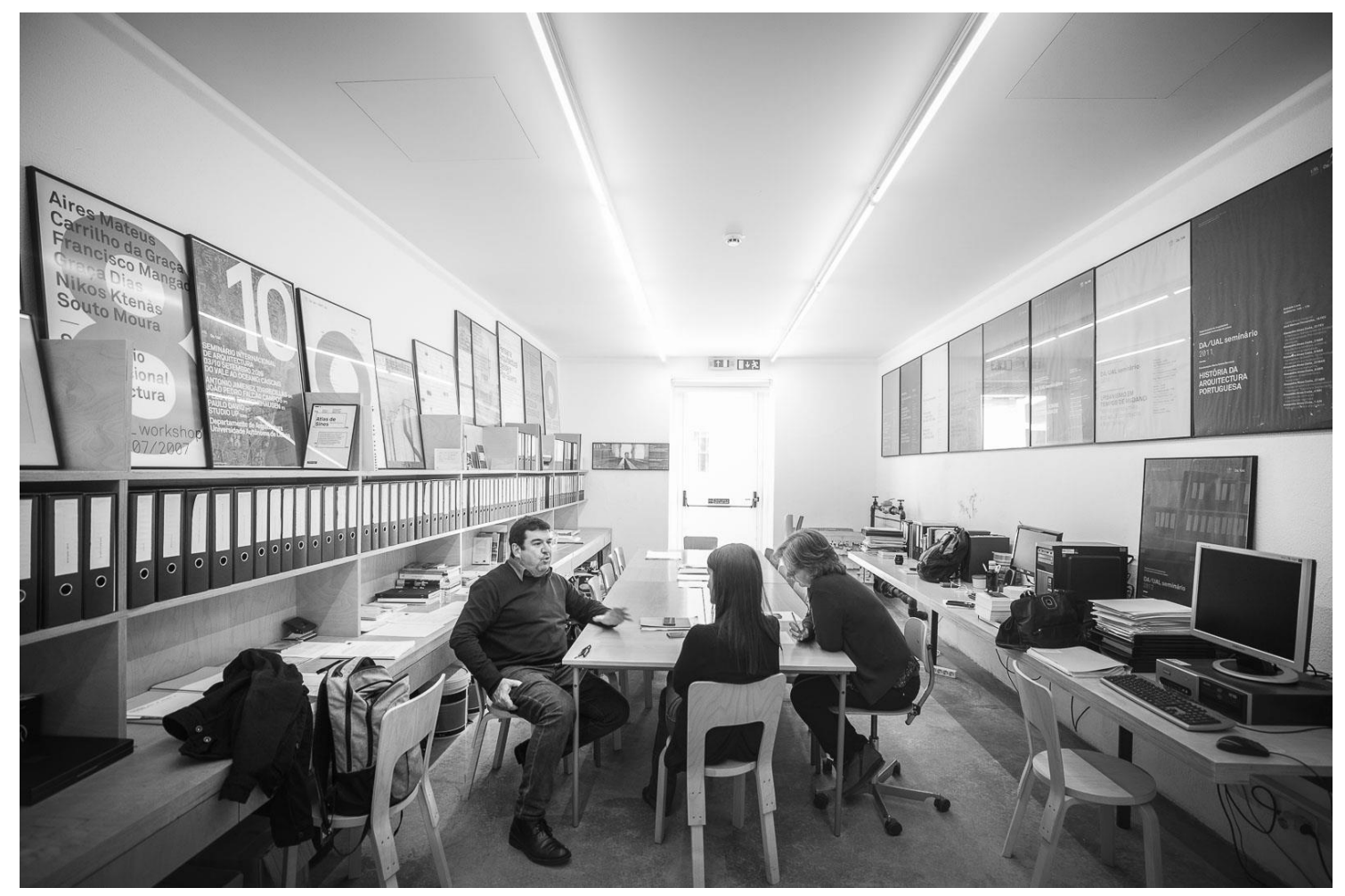

(C)Gonçalo Henriques + Estudo Prévio

Falaste da importância da viagem. A viagem que fizeste ao Porto e em Erasmus... É uma constante dos nossos entrevistados, esta paixão pela viagem. Queres partilhar connosco alguma viagem que tenha tido algum significado especial?

Eu sempre gostei muito de viajar, habituei-me a viajar desde miúdo e venho de uma família em que viajávamos por ócio, pelo prazer da viagem. Lembro-me muito das 
coisas avulso que ficam de cada viagem, mesmo quando és muito pequeno, memórias quase dispersas, mas que são marcantes. Há, às vezes, a ideia de que um miúdo pode ser novo demais para se levar numa viagem. Mas nunca és novo demais para fazer uma viagem, porque vais sempre guardar dessa viagem uma memória que, de alguma forma, é marcante.

Eu fiz bastantes viagens, e fiz algumas viagens extraordinárias com amigos meus, aliás professores desta escola, porque, durante um período de tempo, tínhamos um grupo de amigos que fazia umas viagens que podíamos chamar "viagens disciplinares", porque tínhamos como tema estruturante ver arquitetura. Estou a lembrar-me de uma viagem histórica que fizemos ao México para ver o Barragán. Foi muito marcante, não só pela viagem em si como pela arquitetura que vimos.

Mas faço muitas viagens onde a arquitetura não tem propriamente que ser o motivo. A arquitetura, para mim, extravasa andar a correr atrás de um edifício, de um monumento ou arquiteto. A arquitetura é a minha vida toda desde que acordo (até a dormir, se o colchão é mais mole, é arquitetura, se é duro, também é arquitetura!). Com certeza que as viagens são um tema fundacional, mas, mais do que as viagens, é o estar em movimento. Quando chegamos às fases de desenvolver um pouco mais o projeto e abordamos temas como a construção, o projeto de execução, desenhar um caixilho ou uma porta, eu digo sempre aos meus alunos: "tu hoje até chegares aqui à aula já abriste e fechaste doze portas, não percebo porque não olhaste para nenhuma delas. Todas elas têm um aro fixo, um aro móvel, dobradiças, puxadores, batentes. É só olhar! Depois, vamos ver a tua porta, mas, para já, passaste por doze e não paraste para olhar para nenhuma"!

\section{É a viagem do quotidiano...}

Há uma frase muito bonita do arquiteto Paulo Mendes da Rocha que diz que "a arquitetura aprende-se no caminho para a escola". Eu acho que isso é, de facto, uma grande verdade. 